\title{
Geografías regionales y metropolitanas de la financiarización habitacional en Chile (1982-2015): ¿entre el sueño de la vivienda y la pesadilla de la deuda?
}

Daniel Santana-Rivas. Universidad Nacional de Colombia, Medellín, Colombia.

RESUMEN | Mediante el proceso de financiarización, las políticas neoliberales han convertido los derechos sociales en deuda. En ese sentido, destaca a nivel latinoamericano el caso chileno, donde la temprana interpenetración de las altas finanzas con la provisión de vivienda constituye su verdadera originalidad, además del ya reconocido subsidio a la demanda. El objetivo del artículo es realizar un análisis socioespacial de las geografías regionales y metropolitanas de la deuda hipotecaria entre 1982 y 2015 en Chile. Para ello se asume una lógica dialéctica que subraya tanto la creación y los ajustes que han experimentado los mecanismos de financiarización de la producción del espacio y la vivienda, como el proceso de expansión del endeudamiento acelerado a un mayor ritmo, en el período comprendido entre 2004 y 2015. Se concluye que esa masificación corresponde a distintos sujetos de deuda y que el proceso de sobreendeudamiento plantea interrogantes sobre la posibilidad de futuras crisis.

PALABRAS ClaVe | financiarización, vivienda, política habitacional.

ABSTRACT | Through the process of financialization, neoliberal policies have turned social rights into debt. The Chilean case stands out in Latin American in that sense and it is argued that the early interpenetration of high finance-with the provision of housing-constitutes its true originality in addition to the already recognized subsidy to demand. Consequently, the objective of this article is to conduct a socio-spatial analysis of the regional and metropolitan geographies of mortgage debt between 1982 and 2015. For this, a dialectical logic is assumed, that emphasizes the description both in the creation and the adjustments that they have experienced, the mechanisms of financialization of the production of space and housing, as well as the process of massification of increased indebtedness in the period between 2004 and 2015. Finally, it is concluded that this massification corresponds to different subjects of debt and that the process of over-indebtedness raises questions about the possibility of future crises.

KEYWORDs | financialization, housing, housing policy. 


\section{Introducción}

En una obra muy bien documentada y en extremo sugerente publicada por Rolnik (2017), se describen distintos casos que ilustran procesos contemporáneos de colonización del sector habitacional por parte de las altas finanzas globalizadas, que derivan -según lo plantea la autora- de la expansión de lo que Aalbers (2011) denomina 'complejo financiero-inmobiliario'. Curiosamente, el caso chileno, examinado con cierto detenimiento en ese texto, es tomado simplemente como el laboratorio experimental del modelo de subsidio a la demanda. Sin embargo, aunque ello también es correcto, omite el análisis de otro conjunto de 'singularidades' que posteriormente se convertirían en rasgos estructurales no solo de las políticas públicas de provisión de vivienda, sino también de la regulación de los procesos de producción del espacio urbano. Una de estas particularidades es la financiarización de la producción y del consumo de la vivienda.

La 'revolución neoliberal' (Gárate, 2012), que en Chile comenzó como un viraje macroeconómico hacia lo que en la década de los setenta del siglo pasado se conocía como monetarismo, llegó a consolidarse como una ideología profundamente arraigada en la sociedad chilena a partir de su desdoblamiento en modelo político (Hidalgo, Santana, \& Alvarado, 2016). En el marco de este proceso tuvo lugar una reformulación radical en los modos de producción del espacio urbano y la vivienda, con las políticas de subsidio a la demanda solamente como la cima del iceberg. Tales modos de producción del espacio se constituyeron a partir de un conjunto de instrumentos normativos vinculados, por una parte, a materias de organización territorial -esto es, de la regionalización político-administrativa a la planificación urbana-; y por otra, al financiamiento de la producción (fondos de inversión inmobiliarios, de infraestructuras, ventas de acciones, constitución de sociedades por acciones, entre otros) y del consumo inmobiliario (subsidios, créditos hipotecarios titulizados y securitizados).

A pesar de su ir y venir en el tiempo -de ser creados, desechados, retomados y transformados- estos instrumentos se han vuelto prácticamente estructurales (Santana, 2018a). A los primeros se les denominará aquí mecanismos neoliberales de producción del espacio (MENPE); y a los segundos, mecanismos de financiarización de la producción del espacio (MEFPE). Su uso en un marco ideológico más amplio -la utopía de una sociedad neoliberal instituida en la Constitución de 1981, basada en un capitalismo financiarizado-, que se fue construyendo tempranamente mediante distintas formas de hegemonía (en el sentido gramsciano del término: violencia, coacción y cooptación) desde la década de los setenta, es lo que constituye realmente la verdadera singularidad del 'laboratorio chileno'.

La matriz que constituye esos mecanismos neoliberalizados y financiarizados se compone de elementos que de por sí no son nuevos ni en el marco del desarrollo capitalista ni en el ámbito de los imaginarios sociales, ${ }^{1}$ pero que se articulan actualmente

1 La propiedad es el más claro ejemplo de ello; como señala Capel (2013), dicha relación social se tornó en hecho jurídico desde el derecho romano, e incluso lo antecedió en la realidad social. Y en el caso de la propiedad residencial, tanto en Chile (Alvarado, 2019) como en América Latina ha desempeńado un rol político mucho más definido que en el contexto europeo, donde las formas de tenencia son más diversas; el arrendamiento de viviendas públicas o privadas ha sido más la regla que la excepción en Alemania y, en ciertos momentos, en Reino Unido y Holanda (Aalbers, 2017). 
como una novedosa unidad contradictoria: subsidios, deuda y propiedad. Los tres crean en paralelo, por un lado, nuevas subjetividades sociales que transitan entre la condición de 'sujetos subsidiados', 'sujetos endeudados' (Lazzarato, 2013) y 'sujetos propietarios' (en este caso, de una vivienda), con sus respectivas geografías; y por otro, nuevos espacios urbanos socialmente diferenciados en función de su capacidad portante para realizar capitales financieros a partir de su rentabilidad, potencial de liquidez y riesgo (Santana, 2019). Del primer proceso de subjetivación resultan distintas geografías sociales de la solvencia y de la deuda; y del segundo, diferentes estrategias geopolíticas de instrumentalización del espacio urbano para la reproducción de capitales financieros.

Así, los subsidios, la deuda y la propiedad asumen un significado social y geográfico novedoso en función del proceso de financiarización del capitalismo. Ahora bien, cuando se alude a este proceso, se acude no solo a su definición estrecha, que suele asociarlo únicamente a la titulización, a la imposición de la lógica financiera a las dinámicas de la inversión de capitales (Theurillat, 2010) o la conversión de sujetos y objetos en activos financieros (Aalbers, 2017). También se apunta a una tendencia que hibrida tanto un irrestricto dominio de las finanzas sobre la producción, como a su creciente y masiva penetración en los procesos de reproducción social (Santana, 2018b). Su origen estaría en una caída tendencial de la tasa de la ganancia y, por consiguiente, en una situación de sobreproducción e hipercompentencia que data de la década de los setenta (Arrighi, 1994; Brenner, 1999) y que podría estar amenazando las bases económicas del capitalismo -la acumulación de capital a partir de la producción de nuevo valor- (Kurz, 2016; Wallerstein, 2015).

Aunque un análisis más o menos comprensivo de los mecanismos mencionados y de sus improntas geohistóricas en el Chile contemporáneo es una tarea que escapa a la extensión del presente artículo, existiendo en esa dirección un creciente acervo de trabajos (Alvarado, 2019; Cattaneo, 2011; Daher, 2016; Hidalgo, 2005; Hidalgo et al., 2016; Santana, 2018a), aquí interesa abordar una de las dimensiones clave de las 'geografías de la solvencia': la deuda habitacional. Esa tarea podría ser llevada a cabo estudiando diferentes sujetos endeudados, en función, por ejemplo, de los distintos tipos de crédito hipotecario. En este caso, no obstante, dadas las limitaciones de la información existente ${ }^{2}$ para la escala de análisis planteada (nacional), se partirá de un examen de la realidad espaciotemporal de las deudas habitacionales. En consecuencia, el objetivo del presente artículo es analizar las geografías regionales y metropolitanas de la deuda habitacional en Chile entre 1982 y 2015, en particular los casos de Santiago, Valparaíso y Concepción, ilustrando cuáles MEFPE se asocian a ellas, y cómo han surgido en las distintas fases de la financiarización capitalista ocurrida en el país. La hipótesis es que este proceso ha generado una rápida e intensa expansión del endeudamiento hipotecario en todo el país. Se trata

2 Los datos de endeudamiento hipotecario han sido espacializados por la Superintendencia de Bancos e Instituciones Financieras de Chile (SBIF) solamente a nivel regional, y comunal en el Área Metropolitana de Santiago; sin embargo, a pesar de que sus informes presentan una detallada desagregación respecto de la institución otorgante, en ellos no se ofrece una categorización según tipo de crédito hipotecario para esa escala. 
de un fenómeno hasta cierto punto silenciado en los debates públicos, ${ }^{3}$ que se ha ido desplegando desigualmente en ciertas regiones y metrópolis con mercados de vivienda dinámicos.

En la primera parte se busca ofrecer una respuesta teórica a por qué la producción de la vivienda y lo urbano resulta tan atractiva para otorgar un 'nuevo respiro' al capitalismo en el transcurso de su financiarización neoliberal. Posteriormente, se hacen explícitos algunos elementos del método utilizado para reconstruir las geografías de la deuda habitacional. En la tercera parte se describe de qué manera se construyó la financiarización habitacional en Chile y sus improntas a escala regional, para finalmente identificar algunas de sus implicaciones en el caso de las metrópolis y capitales regionales. Se concluye que la aceleración reciente del endeudamiento hipotecario plantea interrogantes serios sobre su viabilidad futura, en especial en los enclaves más dinámicas donde se ha concentrado, con lo que ello implica en términos de posibilidades latentes de crisis, dinámicas de desposesión y alienación socioespacial.

\section{¿Qué está pasando con la producción de ambiente construido y vivienda en la ciudad del capitalismo neoliberal y fianciarizado?}

La producción capitalista de urbanización y la provisión de vivienda fueron temas que, a lo largo de las décadas de los setenta y ochenta, suscitaron profundos y extensos debates en el ámbito de las teorías urbanas que inspiraron lo que Merrifield (2014) denomina "la vieja cuestión urbana". Así, las obras de Topalov (1979) o Castells (1978) pusieron de relieve no solo ciertas especificidades que presentaba la vivienda en un marco de relaciones sociales capitalistas, sino las interconexiones entre poder financiero, grupos de promotores y el Estado. El denominador común, a pesar de las diferencias conceptuales entre tales autores, era que la vivienda constituía un asunto clave para la reproducción de la fuerza del trabajo y se encontraba dentro del grueso grupo de los medios de consumo colectivo (Santana \& Alzate, 2017).

Los esfuerzos más recientes para evidenciar las continuidades y novedades en la producción del espacio urbano y en la provisión capitalista de vivienda, han sido realizados a partir de la categoría del 'complejo financiero-inmobiliario' de Aalbers (2011), del concepto de 'reestructuración inmobiliaria' propuesto por Pereira (2008) y Lencioni (2014), o del secundary circuit original de Harvey (1990) pero reformulado por Gotham (2012). Todos ellos apuntan a una tendencia muy distinta de la recién señalada: la producción inmobiliaria urbana y la provisión de vivienda serían un foco atractivo para la reproducción del capital, y no tanto para la reproducción de la fuerza del trabajo (labor que usualmente lideraba el Estado keynesiano o el desarrollista en América Latina). Aunque no se hará un contraste entre esas opciones teóricas, todas válidas y por demás complementarias, se plantea de inicio que ese es el punto central para abordar los procesos de financiarización

En ese sentido, el indicador del porcentaje de viviendas en una condición de tenencia asociada al periodo de amortización de la deuda hipotecaria fue excluido, al igual que otros, del ejercicio censal de 2017. 
urbana y de la vivienda. Además, se parte de la premisa de que el denominador común de esos enfoques estaría en la categoría de segundo circuito conceptualizada por Lefebvre (1976), un elemento central en su propuesta para una economía política del espacio.

Dentro del conjunto de hipótesis transductivas lanzadas por Lefebvre (1976, 1980, 2013) para comprender la sociedad urbana contemporánea, se encuentra aquella según la cual la producción inmobiliaria y de infraestructuras, a pesar de (y gracias a) su nivel de atraso técnico, se convertiría en una rama neurálgica para la reproducción del capitalismo. Facilitaría no solo la formación de nueva plusvalía (predominando la absoluta sobre la relativa) a partir de las actividades de construcción, sino también la realización de plusvalías y ganancias provenientes de otras ramas capitalistas con problemas de sobreproducción o con crecientes excedentes financieros. Aunque dejaba entreabiertas dos preguntas en relación a por qué y cómo sucedería dicho proceso, avanzó algunos elementos. Entre ellos, que la producción capitalista de espacio urbano y de la vivienda como tal implica la generación de un producto sui generis que internaliza altas tasas de ganancia de un capital industrial. Tal proceso se sustentaría en una condición de atraso técnico que, por una parte, facilita la obtención de plusvalías absolutas (un grado de explotación más alto de los trabajadores de la construcción); y por otra, requiere de un emplazamiento espacial susceptible de ser convertido en renta y, como tal, en activo financiero (Lefebvre, 1976).

Pues bien, el funcionamiento de la producción inmobiliaria y de la vivienda como segundo circuito de acumulación capitalista (dependiente de los excedentes industriales, comerciales y financieros canalizados por el Estado y las instituciones financieras), que en ciertos momentos se desplazaba al primero (producción de bienes y servicios), podría, bajo ciertas condiciones geohistóricas, permanecer en esa última condición en un contexto donde operase la ley tendencial de la caída de la ganancia. Esa posibilidad teórica se ha vuelto cada vez más factible en contextos donde la neoliberalización y la financiarización del capital han comenzado a emplearse como estrategias para la reproducción del capitalismo; y Chile es un arquetipo de ambos procesos en América Latina. De hecho, aparecen inextricablemente entrelazados desde mediados de los setenta, cuando la producción de espacio urbano y de la vivienda se asoció con el desarrollo de un mercado de capitales con instrumentos de inversión para el largo plazo y con la conversión de la planificación urbana en una actividad de gestión estratégica de los usos del suelo en función de su rentabilidad privada -aunque disfrazada con el vago términos de 'rentabilidad social'- (Santana, 2018a). Esa tendencia podría estarse superponiendo a los ciclos espaciotemporales de producción de ambiente construido teorizados por Harvey (1990, 1985, 2013), que derivan de las fluctuaciones periódicas de la tasa de ganancia en el primer circuito de producción (Santana, 2018a).

La producción de espacio urbano y de vivienda ofrece, así, una nueva y atractiva frontera para la reproducción del capitalismo. Ello particularmente en un contexto de economías urbanas y metropolitanas marcadas por procesos de desindustrialización, donde están teniendo lugar fenómenos muy incipientes de reconversión hacia las actividades del capitalismo cognitivo y cultural (cuya posibilidad para la 
reproducción capitalista es totalmente incierta) y una proliferación de actividades 'cuaternarias' impulsadas por las finanzas. Y, sobre todo, frente a la caída de las tasas de ganancias industriales y a un excedente de capitales financieros ociosos que buscan completar su ciclo DD' sin atención al lugar donde esto se lleve a cabo (Daher, 2013; De Mattos, 2015). Prueba de lo anterior son las crisis locales o globales, recurrentes desde los años setenta, que estallan en los mercados inmobiliarios (de Japón en los noventa, al sureste asiático a fines de esa década, de Estados Unidos con la gran crisis global de 2008), y que en las teorías económicas críticas siguen sin pensarse como un movimiento en conjunto, apareciendo simplemente como explosiones individuales que surgen de distintos 'fenómenos nacionales' de especulación.

Una economía política del espacio que aborde la financiarización de la vivienda debe también articular tales procesos globales y estatales a la producción de sujetos y espacios sociales. Así, los procesos macrosociales que operan para convertir lo que antes eran derechos sociales (entre ellos, la vivienda) en deuda social, se expresan en nuevas relaciones de poder que surgen entre acreedores y deudores, entre subsidiantes y subsidiados (Lazzarato, 2013). Estas relaciones se articulan a través de formas de control que van desde la evaluación moral de la solvencia o de la 'aptitud' para el subsidio, pasando por el condicionamiento de las acciones y posibilidades futuras de los individuos u hogares, hasta la determinación de su localización en el espacio urbano en función de su solvencia. De esa manera hay tres tipos de producción de subjetividades vinculadas a la financiarización de la vivienda:

- El sujeto subsidiado, que es resultado de los procesos de disciplinamiento financiero (ahorro programado, por ejemplo), de 'evaluación moral estatal' (nivel de vulnerabilidad medido con encuestas o fichas, capacidad de competencia con otros individuos) y de 'evaluación moral financiera' (criterios de asignación de crédito hipotecario según solvencia).

- El sujeto endeudado (Lazzarato, 2013), al cual las instituciones financieras condicionan sus posibilidades de acción futura, puesto que no debe quedar desempleado y, en caso de crisis financiera, debe pagar no solo sacrificando su propiedad, sino su acceso a otros derechos sociales (recortes presupuestales).

- El sujeto propietario, que es la construcción ideológica sobre la cual reposa cualquier intento de sociedad liberal, o neoliberal en este caso; de todas formas, la propiedad habitacional pasa a ser el último elemento de reserva de ingresos familiares en un contexto de deflación salarial.

Estas subjetividades van asociadas a determinadas geografías sociales urbanas, que se despliegan a partir de una dialéctica entre:

- Geografías de la solvencia individual y familiar, es decir, dónde están quienes serán sujetos potenciales de subsidios y créditos.

- Geografías de la deuda, que expresan la espacialización de los deudores habitacionales, segmentados en distintas capas de subsidios y tipos de créditos hipotecarios, y que en el curso de las crisis pueden transformarse en las geografías de la insolvencia y, por consiguiente, de la desposesión habitacional (desahucios). 
- Geografías de la rentabilidad financiarizada, es decir, la división de los espacios sociales en función de su capacidad portante para la rentabilidad, la liquidez y la minimización del riesgo (este último parámetro es el menos importante de los tres en el contexto de la financiarización contemporánea).

\section{Cuestiones de método y metodología}

El presente ejercicio de economía política espacial crítica es producto de una investigación más amplia de corte dialéctico (Santana, 2018a). Lo anterior implica señalar que las geografías de la deuda habitacional son un proceso socioespacial que se ha ido desplegando desigualmente sobre el territorio chileno a partir de la instrumentación, a escala nacional, de mecanismos neoliberales de producción del espacio (MENPE) y de mecanismos de financiarización de la producción del espacio (MEFPE). En el presente artículo se intenta profundizar en los últimos y, dentro de ellos, en los instrumentos de financiarización del 'consumo habitacional'.

La distinción entre los mecanismos señalados suele pasarse por alto en la literatura sobre la financiarización de la vivienda, por lo cual se pierde gran parte de la capacidad analítica del concepto. A pesar de la especificidad nacional que ellos puedan asumir, se plantea una clasificación que, sin ánimo de ser exhaustiva y exclusiva, provee un punto de partida útil para el rastreo de los procesos de neoliberalización y financiarización de la producción del espacio urbano y la vivienda a partir de elementos comunes, identificables en casos como el de Estados Unidos, Reino Unido, España y otros latinoamericanos, como Chile y Colombia (tabla 1).

\begin{tabular}{|c|c|c|}
\hline $\begin{array}{c}\text { ESFERA/ } \\
\text { MECANISMO }\end{array}$ & $\begin{array}{c}\text { MECANISMOS DE NEOLIBERALIZACIÓN } \\
\text { DE LA PRODUCCIÓN DE ESPACIO } \\
\text { URBANO }\end{array}$ & $\begin{array}{c}\text { MECANISMOS DE FINANCIARIZACIÓN } \\
\text { DE LA PRODUCCIÓN DE ESPACIO } \\
\text { URBANO }\end{array}$ \\
\hline \multirow{3}{*}{$\begin{array}{l}\text { Producción } \\
\text { habitacional }\end{array}$} & \multirow{2}{*}{$\begin{array}{l}\text { Reordenamiento institucional: privatiza- } \\
\text { ción o liquidación de instituciones públicas } \\
\text { de promoción y financiamiento habita- } \\
\text { cional directo, y creación de entidades } \\
\text { público-privadas con lógica de mercado, a } \\
\text { menudo descentralizadas. }\end{array}$} & $\begin{array}{l}\text { Nuevos instrumentos de centralización y } \\
\text { concentración del capital financiero para } \\
\text { inversión inmobiliaria: participación de } \\
\text { inmobiliarias en Bolsa y configuración de } \\
\text { fondos de inversión con participación de } \\
\text { fuertes inversores institucionales. }\end{array}$ \\
\hline & & $\begin{array}{l}\text { Creación de filiales inmobiliarias de } \\
\text { bancos, empresas y otras instituciones } \\
\text { financieras; nuevo ordenamiento empre- } \\
\text { sarial en estructuras de holding, formas de } \\
\text { articulación empresarial flexible (sociedades } \\
\text { por proyecto). }\end{array}$ \\
\hline & $\begin{array}{l}\text { Descentralización político-administrativa } \\
\text { y autonomización presupuestaria local: } \\
\text { tendencia hacia la individuación territorial } \\
\text { y la competencia nacional e internacional. }\end{array}$ & $\begin{array}{l}\text { Cada unidad territorial se vuelve 'sujeto } \\
\text { territorial' de crédito y se somete a criterios } \\
\text { de gobernanza corporativa y calificaciones } \\
\text { crediticias: hace que se facilite la atracción } \\
\text { de ciertos segmentos sociales para capta- } \\
\text { ción de impuestos. }\end{array}$ \\
\hline
\end{tabular}




\begin{tabular}{|c|c|c|}
\hline $\begin{array}{c}\text { ESFERA/ } \\
\text { MECANISMO }\end{array}$ & $\begin{array}{c}\text { MECANISMOS DE NEOLIBERALIZACIÓN } \\
\text { DE LA PRODUCCIÓN DE ESPACIO } \\
\text { URBANO }\end{array}$ & $\begin{array}{c}\text { MECANISMOS DE FINANCIARIZACIÓN } \\
\text { DE LA PRODUCCIÓN DE ESPACIO } \\
\text { URBANO }\end{array}$ \\
\hline \multirow{3}{*}{$\begin{array}{l}\text { Producción } \\
\text { habitacional }\end{array}$} & $\begin{array}{l}\text { Enclaves de desregulación o regulación } \\
\text { desregulada en áreas periféricas (urbanas, } \\
\text { metropolitanas o en bordes de regiones } \\
\text { urbanas). }\end{array}$ & $\begin{array}{l}\text { Crea áreas con características específicas } \\
\text { que se caracterizan por una alta rentabili- } \\
\text { dad, baja liquidez (en las primeras etapas } \\
\text { sobre todo) y alto riesgo (localizaciones } \\
\text { nuevas, no siempre coincidentes con } \\
\text { patrones clásicos de segregación). }\end{array}$ \\
\hline & $\begin{array}{l}\text { Enclaves de desregulación o regulación } \\
\text { desregulada en áreas centrales, pericentrales } \\
\text { y consolidadas de la ciudad. }\end{array}$ & $\begin{array}{l}\text { Las áreas de este tipo pueden tener una } \\
\text { rentabilidad menor, pero mayor liquidez y } \\
\text { bajo riesgo, dada su localización } \\
\text { privilegiada. }\end{array}$ \\
\hline & $\begin{array}{l}\text { Constitución de políticas de integración } \\
\text { social y 'derecho subsidiario a la ciudad', } \\
\text { que ofrecen incentivos para la producción } \\
\text { público-privada de nuevas centralidades } \\
\text { periféricas e intraurbanas. }\end{array}$ & $\begin{array}{l}\text { El desarrollo habitacional se vincula a la } \\
\text { constitución de centralidades comerciales } \\
\text { y de servicios en grandes extensiones } \\
\text { territoriales periféricas, constituyéndose } \\
\text { en un conjunto de activos financieros } \\
\text { interligados. }\end{array}$ \\
\hline \multirow{7}{*}{$\begin{array}{l}\text { Provisión } \\
\text { (consumo) } \\
\text { habitacional }\end{array}$} & \multirow{3}{*}{$\begin{array}{l}\text { La vivienda se convierte en un bien durable } \\
\text { al que se accede por esfuerzo individual y } \\
\text { competencia (en asignación de subsidios } \\
\text { y/o créditos). }\end{array}$} & $\begin{array}{l}\text { Estructuración del modelo de subsidio } \\
\text { directo (según segmento social y programa) } \\
\text { e indirecto (a tasas de interés hipotecarias) }\end{array}$ \\
\hline & & $\begin{array}{l}\text { Nuevos instrumentos de crédito hipote- } \\
\text { cario articulados a mercados secundarios: } \\
\text { titulización (venta de títulos individuales) } \\
\text { y securitización (venta de paquetes integra- } \\
\text { dos y no individualizados). }\end{array}$ \\
\hline & & \multirow{2}{*}{$\begin{array}{l}\text { Facilidades de acceso al crédito hipotecario } \\
\text { sea mediante abaratamiento del crédito o } \\
\text { a partir de crédito para segmentos de alto } \\
\text { riesgo. }\end{array}$} \\
\hline & $\begin{array}{l}\text { Modelo de política pública subsidiaria } \\
\text { orientada exclusivamente al acceso en } \\
\text { propiedad. }\end{array}$ & \\
\hline & $\begin{array}{l}\text { Privatización de stocks públicos de terrenos } \\
\text { y viviendas. }\end{array}$ & $\begin{array}{l}\text { Conversión de bienes públicos en activos } \\
\text { financieros particulares de hogares o de } \\
\text { empresas y grupos de inversores. }\end{array}$ \\
\hline & $\begin{array}{l}\text { Aparición de nuevos agentes de provisión } \\
\text { de viviendas al margen del Estado: ONG, } \\
\text { entidades público-privadas, gestores con o } \\
\text { sin ánimo de lucro. }\end{array}$ & \multirow{2}{*}{$\begin{array}{l}\text { Creciente segmentación de la oferte de } \\
\text { subsidios y de créditos para atender hogares } \\
\text { de ingresos bajos, medio-bajos y medios. }\end{array}$} \\
\hline & $\begin{array}{l}\text { Estrategias descarnadas de focalización } \\
\text { (reducción de estándares habitacionales) } \\
\text { o de desfocalización con rostro humano } \\
\text { (elevación del estándar cualitativo). }\end{array}$ & \\
\hline
\end{tabular}

TABLA I | Mecanismos de neoliberalización y financiarización de la producción de espacio: MENPE y MEFPE

FUENTE: SANTANA (2019)

Se hace necesario, además, contrastar elementos historiográficos sobre tales mecanismos de financiarización con elementos prácticos en materia de producción de geografías de la deuda habitacional. En ese sentido, en la tabla 2 se enuncian dos de los procesos espaciales que constituyen esas geografías, a partir de las variables, indicadores y fuentes disponibles. En primer lugar, se construyó una serie histórica sobre el stock regional de las deudas hipotecarias, disponible desde 1983, que se pone en relación tanto con las colocaciones totales como con las que se orientan los créditos 
de consumo. Posteriormente, se construyó otra serie histórica más desagregada, que facilita la identificación de las geografías de la deuda a nivel comunal a partir de la variable 'condición de tenencia de la vivienda' en la categoría de propiedad no definitiva (en proceso de amortización) que estuvo disponible en los censos de 1992 y 2002.

\begin{tabular}{|c|c|c|c|c|}
\hline PROCESOS & VARIABLE & INDICADOR & \begin{tabular}{|c} 
NIVEL DE \\
DESAGREGACIÓN \\
ESPACIAL
\end{tabular} & FUENTE \\
\hline \multirow{4}{*}{$\begin{array}{l}\text { Geografías } \\
\text { regionales } \\
\text { de la deuda } \\
\text { hipotecaria. }\end{array}$} & \multirow{4}{*}{$\begin{array}{l}\text { Saldo en } \\
\text { créditos } \\
\text { hipotecarios a } \\
\text { precios } \\
\text { corrientes } \\
(1983-2015)^{*}\end{array}$} & $\begin{array}{l}\text { Stock de deuda hipotecaria a } \\
\text { precios corrientes de cada año. }\end{array}$ & \multirow{4}{*}{ Regional. } & \multirow{4}{*}{$\begin{array}{l}\text { Superintenden- } \\
\text { cia de Bancos } \\
\text { e Instituciones } \\
\text { Financieras } \\
\text { (sBIF), Chile } \\
(1983-2015) \text {. }\end{array}$} \\
\hline & & $\begin{array}{l}\text { Índice de intensidad del } \\
\text { endeudamiento per cápita: } \\
\text { Deuda media a precios corrientes } \\
\text { de cada ańo/población media } \\
\text { del periodo en cada región, en } \\
\text { puntajes estandarizados. } \\
\text { Porcentaje de participación regio- } \\
\text { nal en deuda habitacional. }\end{array}$ & & \\
\hline & & $\begin{array}{l}\text { Porcentaje de créditos hipotecarios } \\
\text { en relación con otras colocaciones. }\end{array}$ & & \\
\hline & & $\begin{array}{l}\text { Razón entre créditos de hipoteca- } \\
\text { rios y créditos de consumo. }\end{array}$ & & \\
\hline $\begin{array}{l}\text { Geografías } \\
\text { metropolitanas } \\
\text { de la deuda } \\
\text { hipotecaria. }\end{array}$ & $\begin{array}{l}\text { Condición } \\
\text { de tenencia } \\
\text { (pagada par- } \\
\text { cialmente). }\end{array}$ & Variación intercensal. & $\begin{array}{l}\text { Comunal en las } \\
\text { Áreas Metropoli- } \\
\text { tanas de Santiago } \\
\text { (AMS), Concepción } \\
\text { (AMC) y Valparaíso } \\
\text { (AMV). }\end{array}$ & $\begin{array}{l}\text { Instituto } \\
\text { Nacional de } \\
\text { Estadísticas } \\
\text { (INE) (1982, } \\
\text { 1992, 2002). }\end{array}$ \\
\hline
\end{tabular}

PARA LOS TRES PRIMEROS INDICADORES CALCULADOS CON ESTA VARIABLE SE EMPLEÓ LA DiVISIÓN POLÍTICO-ADMINISTRATIVA ANTERIOR A LA ACTUAL, EN I 3 REgIONES, A FIN DE FACILITAR LA COMPARACIÓN DE LARGO PLAZO, PUESTO QUE LAS CIFRAS DE LAS NUEVAS REGIONES XIV Y XV SON POSTERIORES AL AÑO 2008.

TABla 2 | Procesos, indicadores y fuentes para el estudio de las geografías de la deuda habitacional en Chile

FUENTE: ELABORACIÓN PROPIA

Aunque se intentó construir una serie de datos de pasivos hipotecarios y de ejecuciones de créditos habitacionales y los datos están muy bien contabilizados a nivel nacional, su limitada desagregación territorial dificulta su análisis geográfico. En todo caso, reviste más importancia analizar las geografías de la deuda a partir de los stocks hipotecarios pasados y presentes, ya que es esa variable la que no solo da cuenta de la intensidad desigual asociada a distintos mercados habitacionales, sino que incluso anuncia qué territorios son más vulnerables a futuras crisis (Daher $\&$ Moreno, 2016), develando la magnitud del capital a crédito y ficticio ${ }^{4}$ generado en la esfera del consumo habitacional en las últimas décadas.

4 El capital a crédito es una forma básica de capital ficticio en la cual se mantiene cierta visibilidad entre deudor y acreedor, así como entre lo prestado y el activo que lo respalda; en cambio, ciertas formas de capital ficticio, como los títulos y bonos, son de un carácter más abstracto, con lo cual se difuminan ambas relaciones. Véase en ese sentido la distinción que hace Harvey (1990) a partir del análisis marxista de las finanzas. 


\section{Produciendo las geografías de la deuda habitacional: procesos y patrones socioespaciales}

La historiografía espacial de la financiarización del consumo habitacional es en Chile más larga que la de la producción inmobiliaria. La implantación hacia finales de la década de los setenta de un modelo subsidiario de provisión de vivienda social estuvo acompañada no solo de la instrumentación de la evaluación social (ficha CAs ${ }^{5}$ ) y de los subsidios, con todos los desplazamientos ideológicos asociados -individualismo, competencia y conversión de la vivienda en un bien de consumo- (Hidalgo, 2005), sino también de la articulación de los créditos hipotecarios al mercado de capitales que operan en plazos largos. Por esa razón se hace necesario indagar en los orígenes de ese último proceso.

Un análisis de El Ladrillo (Centro de Estudios Públicos [CEP], 1992 [1973], el programa que fue propuesto por los Chicago Boys al gobierno dictatorial tras el golpe de Estado en 1973, revela efectivamente una preocupación por construir un mercado de capitales, que sería el ámbito neurálgico para la "asignación eficiente" de las inversiones entre sectores y regiones. Tal mercado debía tener asociados circuitos con temporalidades diversas: en al ámbito del largo plazo, el eje central serían los fondos de pensiones privados. Estos fondos, además de garantizar una gran centralización y concentración de ingresos y una supuesta eficiencia en la asignación de inversiones hacia sectores de larga duración, como la construcción, aliviarían las tensiones entre capital y trabajo mediante la 'propiedad' de activos financieros:

Un sistema previsional basado en "Fondos" de ahorro efectivo de los participantes no sólo es una solución eficiente al problema previsional, sino que además creará un mecanismo de acumulación de riqueza en manos de los trabajadores. Ellos pasarían a ser, con el tiempo, una de las principales fuentes de ahorro para financiar inversiones, pudiendo alcanzar un papel prominente como poseedores de capital. Si esta posibilidad se materializa, podrían desaparecer o aminorarse las tensiones entre el capital y el trabajo, ya que este último sería a su vez poseedor de importantes recursos de capital. (CEP, 1992 [1973], p. 134; destacados propios)

En un documento menos conocido pero equiparable al anterior, en el sentido de ser un programa para la acumulación de capital, aunque pensado específicamente en el ámbito de la construcción de vivienda e infraestructura y que fue publicado en noviembre de 1973 por la Cámara Chilena de la Construcción (CCHC), se esbozó una propuesta que articulaba ese mercado de capitales de largo plazo y la financiación habitacional. En ese Plan Habitacional y de Desarrollo Urbano 1974-1979 (сCHC, 1973, pp. 49-50) se sugiere:

La Ficha Cas remite a los Comités de Asistencia Social (CAS), instancias de nivel comunal encargadas de la ejecución de los programas sociales del Estado. Es el nombre con que se conoció la Ficha de Protección Social (FPS), instrumento creado en 1979 y reemplazado a partir del 1 de enero de 2016 por el Registro Social de Hogares, un sistema de información cuyo fin es apoyar los procesos de selección de beneficiarios de subsidios y programas sociales. 
El sistema previsional chileno ha significado una burla para los imponentes. Actualmente los recursos que debieran ser de capitalización se usan en parte para cubrir las obligaciones de reparto o se queman en financiar una burocracia improductiva. A pesar de ello los excedentes han sido una fuente tradicional de recursos para el sector vivienda (...). Cualesquiera [sic] que sea el sistema que definitivamente se aplique al régimen provisional debe considerar que el sector vivienda tiene que contar con una cuota importante de la recaudación de capitalización de las cotizaciones previsionales (...). Sería conveniente estudiar el gran impacto psicológico que significaría que los trabajadores de distintas actividades el que tengan en el Sinap o en Corhabit, las cotizaciones de capitalización (8,33\%, etc.) a su nombre y que ellas le hagan alcanzable en un plazo más corto el sueño de la casa propia" (...). Si definitivamente el sistema previsional se encauza a sociedades del tipo financiero en los que ellas manejen sus recursos de capitalización, de acuerdo al mercado de capitales competitivo, deberán estudiarse y establecerse los mecanismos que obliguen a que una parte importante de estos recursos se coloquen en bonos, pagarés, $V H R^{6}$ del sector vivienda. (Destacados propios)

Una de las propuestas en ese último caso era la siguiente:

Deberán estudiarse los mecanismos financieros y legales que permitan nuevamente encauzar el crédito externo al sector vivienda, ya sea por créditos subvencionados de las instituciones internacionales para la vivienda de interés social o por medio de venta de hipotecas a organismos privados de los países desarrollados, siendo cargo del Estado los riesgos de cambio que ello involucre. (сснс, 1973, p. 50)

Esa venta de hipotecas y la colocación de bonos y pagarés asociados a ellas constituyó una primera propuesta de titulización de la deuda habitacional, que se proyectaba como un instrumento de inversión apto para los fondos de pensiones privados y para otro tipo de fondos de inversión; es decir, la cCHC propuso en 1973 la construcción de un mercado secundario de capitales en el cual se transara la deuda hipotecaria. Aunque en el documento se argumenta que dicho mecanismo se inspiraba en el uso del mismo por parte de las agencias de provisión de vivienda social en Estados Unidos (Fannie Mae y Freddie Mac), tanto la propuesta como su posterior aplicación (no exactamente como se planteó en ese momento) podrían ser consideradas como el primer intento de financiarización habitacional en América Latina.

En 1977 y en el marco de liquidación del Sistema Nacional de Ahorro y Préstamo (Sinap), junto con la neoliberalización profunda de la provisión habitacional que convirtió la vivienda en un bien de consumo al que se accedía mediante el esfuerzo individual (simbolizado en ahorro y capacidad de endeudamiento), se implementó el uso de la letra hipotecaria. Ello se hizo a partir del Decreto Supremo 188 de 1978, que estableció las bases del "Subsidio General Unificado" (sGU), el cual implicaba la conversión de la deuda hipotecaria en un título que el banco otorgante transaría en el mercado secundario para la compra por parte de inversionistas. Aunque esa medida se proyectó para masificar la participación de la banca privada en la

Los Valores Hipotecarios Reajustables (vHR) eran títulos de deuda emitidos por las Asociaciones de Ahorro y Préstamo que integraban el Sistema Nacional de Ahorro y Préstamo (Sinap). 
financiación habitacional, en sus primeros años de vigencia tuvo poco éxito y debió ser asumida principalmente por el Estado: a partir de los Servicios de Vivienda y Urbanización (Serviu), ${ }^{7}$ se generaban letras hipotecarias que eran compradas por el Banco del Estado (al menos entre 1977 y 1980), previo a la privatización de las pensiones y el surgimiento de las Administradoras de Fondos de Pensiones (AFp), que ya en la década de 1980 concentraban entre el 44\% y el $49 \%$ de la compra de letras en el mercado secundario (Corporación de Investigación, Estudio y Desarrollo de la Seguridad Social [Ciedess], 1995).

En 1988 se dio otro paso hacia la financiarización del consumo de la vivienda. Se crearon los mutuos hipotecarios endosables, que buscaban ser títulos de deuda con menores costos de transacción y que presentaban tasas de interés más altas, puesto que fueron diseńados para financiar la vivienda y la compra de propiedades no residenciales en proporciones de hasta $80 \%$ y plazos potenciales de hasta 40 ańos. En un principio eran los bancos comerciales y luego las Administradores de Mutuos Hipotecarios (nuevas instituciones financieras) las que podían emitirlos. Aunque en un principio las AFP no estaban facultadas para comprarlos, se abrió la puerta a su uso para las compañías de seguros, los fondos mutuos y luego a los de inversión y a las sociedades inmobiliarias. Esto se debía a que el riesgo era mayor y su liquidez menor que en el caso de las letras. No obstante, los mutuos fueron diseńados con miras a implementar procesos de securitización, y serían finalmente instrumentalizados por el Estado a mediados de los noventa.

Aunque estos dos mefpe fueron los principales instrumentos de deuda habitacional hasta finales de los noventa, la llegada masiva de la banca privada española en ese momento facilitó, a partir de la instrumentación de mutuos hipotecarios no endosables, una 'rebancarización' de la deuda hipotecaria y, por consiguiente, un acceso al crédito más barato. De hecho, aunque en Chile no hay instrumentos similares a las subprime estadounidenses, este tipo de crédito, mucho más barato que el ofrecido mediante letras y mutuos hipotecarios endosables, se masificó y ha venido desplazándolos porcentualmente desde entonces. Las cifras asociadas a cada MEFPE no se encuentran georreferenciadas sino agregadas a nivel nacional, lo que solo permite identificar un crecimiento intenso entre 2004 y 2015, que coincide con la introducción de los mutuos hipotecarios no endosables (figura 1).

Si se observa el periodo comprendido entre 1970 y 2016 a partir de dos estimaciones distintas del peso del endeudamiento hipotecario en relación al PIB, y a pesar de divergencias de consideración entre las series comparadas (figura 2), es posible sostener que, desde 1981, el crecimiento del endeudamiento no ha descendido de $5 \%$ respecto al PIB y que esta relación se ha disparado desde finales de los noventa. Esta financiarización ha derivado más de la masificación del crédito barato de los mutuos hipotecarios no endosables (en relación a los otros mefre) que de los endosables, cuya emisión y securitización presentan una baja representación en relación con los anteriores y con las letras. De esa manera, Chile -a pesar de estar lejos de los

7 Los Servicios de Vivienda y Urbanización (sERviu) eran agencias regionales del Ministerio de Vivienda y Urbanismo que surgieron primero como promotoras y financiadoras y que han devenido luego en 'gestoras' descentralizadas. Son producto del proceso de reestructuración neoliberal del modelo de vivienda social. 
niveles de deuda hipotecaria en relación al PIB nacional de países como Dinamarca ( $114 \%$ en 2013$)$, Holanda (101,2\% en 2012$)$ o España $(62,9 \%$ en su punto más alto en 2009) (CEsifo DiCE, 2015) - presenta uno de los más altos en América Latina, junto a Panamá, llegando a 24\%, diferenciándose poco del que existía antes de las crisis en países como Grecia $(29,8 \%)$.

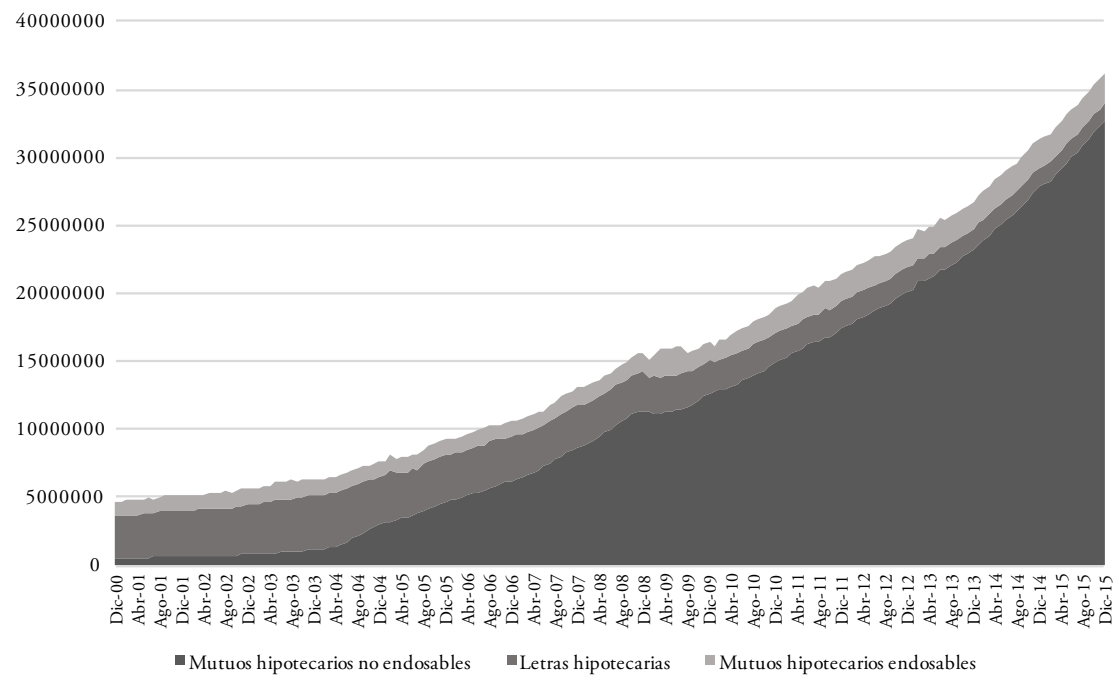

NOTA: MONTO DE LAS OPERACIONES EN STOCK EN MILLONES DE PESOS DE CADA AÑO

FIGURA I | MEFPE entre los años 2000 y 2015 en Chile

FUENTE: ELABORACIÓN PROPIA A PARTIR DE SBIF (2OI7)

Ahora bien, para caracterizar los procesos de cambios en las geografías regionales de la deuda hipotecaria se emplearon tres periodos: el primero, 1983-1989, coincide con los ańos finales de la dictadura militar, durante los cuales se consolidó la letra hipotecaria; el segundo incluye el regreso a la democracia -con los gobiernos de la Concertación-y el boom del millón de viviendas construidas entre 1990 y 2003, en el que se combinaban letras y mutuos endosables (estos siempre en una muy baja proporción); finalmente está el periodo comprendido entre 2004 y 2015, en el cual se rebancarizaron los créditos hipotecarios y los otros dos MEFPE. En la figura 3 se ilustran esos tres momentos, el peso porcentual promedio anual de las colocaciones hipotecarias en relación con las colocaciones totales, que abarcan otros créditos de consumo y a la producción (incluye la construcción). 


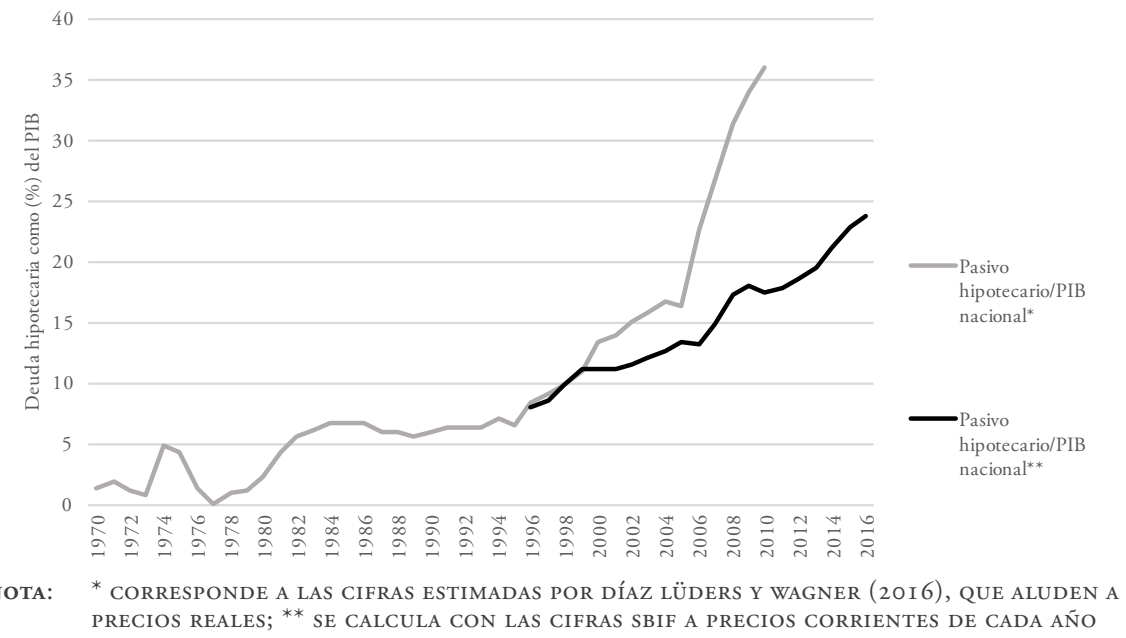

FIgURA 2 | Deuda hipotecaria como porcentaje del PIB nacional

FUENTE: ELABORACIÓN PROPIA A PARTIR DE DÍAZ ET AL. (20I6) y SBIF (20I7)

Aunque se intentó construir los mapas con intervalos constantes para facilitar la comparación, ello fue imposible dado el fuerte aumento del peso de las colocaciones hipotecarias por sobre las totales, con cambios extremadamente abruptos. De esa manera, entre 1983 y 1989, en las regiones de Antofagasta, Valparaíso y Metropolitana esta última relación -peso de las colocaciones hipotecarias por sobre las totales- fue más alta que en las demás, con 6,1\%,7\% y 13,5\%, respectivamente, frente a un promedio de 3,9\% para todas las regiones (figura 3). Lo que demuestran esas cifras es que a pesar de que en ese momento la letra hipotecaria era el MEFPE más importante para acceder a una vivienda, el endeudamiento era bajo, producto de un lento ritmo de la construcción habitacional posterior a la crisis de 1982 (Hidalgo, 2005), aunque tendía a ser mayor en las regiones más urbanizadas: la Metropolitana y la de Valparaíso y en menor medida en Antofagasta, una de las 'regiones ganadoras' en ese momento, cuando la economía giraba en torno a la minería del cobre.

Entre 1990 y 2003, la producción masiva de viviendas sociales impulsada por los gobiernos democratacristianos, combinada con la masificación de los MEFPE (ya articulados a un creciente y poderoso mercado de capitales), implicó un aumento del promedio regional a $14 \%$. Hubo una redistribución espacial del peso de las colocaciones hipotecarias, pasando a ser Antofagasta la región en la que esa relación fue mayor (21\%), seguida de la Metropolitana (17\%); en las regiones del norte el aumento fue muy significativo y en el sur alcanzó a Biobío y La Araucanía en niveles de entre $14 \%$ y $16 \%$. Esa distribución regional señala que las geografías de la deuda hipotecaria alcanzaron mayores niveles tanto en las regiones con las metrópolis más importantes del país, como en las regiones económicamente dinámicas con mercados de vivienda que incluyen segmentos especulativos -para inversión, alquiler o segunda residencia-, como las del norte del país, por ejemplo. 
Finalmente, entre 2004 y 2015 el promedio regional alcanzó un 31\%, y en términos espaciales se dio una descentralización de los pesos de los créditos hipotecarios en el portafolio de colocaciones financieras (figura 3): en el eje norte, incluyendo desde la Región de Antofagasta a la Región de Valparaíso, el promedio alcanzó un 36\%, siendo más alto de nuevo en Antofagasta (44\%). Al sur la cifra media fue menor, $28 \%$, concentrándose los valores más altos en las regiones de La Araucanía y Biobío. En contraste, la Región Metropolitana tuvo un peso de las colocaciones hipotecarias menor al promedio nacional (20\%), lo que de igual manera representa que un quinto de los capitales financieros para préstamos se colocó en el renglón de la financiación habitacional.

Lo anterior implica una atenuación de los ritmos del endeudamiento (aunque persisten igualmente altos niveles absolutos de endeudamiento) en el centro del país y una aceleración en casi todas las demás regiones. El MEFPE asociado a este proceso fue sin duda el mutuo no endosable más difundido social y espacialmente, y ello gracias dos circunstancias: es más barato que los transados en mercados de capitales, y ha sido otorgado por la banca, la cual, pese a su centralización en pocas pero poderosas instituciones, presenta un gran alcance territorial. Lo que también revela el peso creciente de los créditos hipotecarios en el total de las colocaciones es que ha disminuido el flujo de recursos hacia las deudas asociadas a la producción. Lo anterior atañe incluso a los créditos a la construcción, lo que deja abierta la pregunta respecto de si la desintermediación bancaria y la búsqueda de capitales en los mercados financieros serán estrategias suficientes y viables para mantener las condiciones de reproducción del capital en la esfera productiva.

Esa creciente primacía de la deuda hipotecaria se puede rastrear incluso en otro segmento sujeto a los procesos de financiarización: el consumo. En la figura 4 se evidencia la razón entre el monto promedio de los créditos hipotecarios y el de los créditos de consumo, que al ser menor de 1 denota una preeminencia de los últimos sobre los primeros; y que al ser mayor a 1 refleja un desbalance hacia la deuda hipotecaria. Así, entre 1983 y 1989 solamente la Región Metropolitana -la más impactada por la crisis de 1982 (Daher, 2016; Santana, 2018a)- presentó una preeminencia de la razón entre créditos hipotecarios y de consumo, mientras en las demás regiones esa relación era inversa; tal situación tuvo una leve variación en el siguiente periodo, para revertirse casi por completo entre 2004 y 2015. Lo anterior, además de sugerir conexiones entre la financiarización de la vivienda y la del consumo -aun poco exploradas en la investigación social y urbana chilena-, indica que los sujetos endeudados se encontraban, cada vez más, inmersos en créditos que cubren distintas escalas temporales de su vida.

La financiarización del consumo de vivienda ha facilitado así en todo el país, a nivel regional, una expansión del endeudamiento hipotecario, además de una intensificación de ese ritmo por encima del promedio en las regiones más urbanizadas o con mercados habitacionales dinámicos. Y al hacer un acercamiento a la escala de las principales regiones metropolitanas -Santiago, Concepción y Valparaíso- en el único periodo para el cual se cuenta con datos censales contrastables (1992 y 2002), se confirma que esa lógica regional se replica en las mismas. 
Así, en el periodo comprendido entre 1992 y 2002, incluido en el lapso intermedio ya analizado que coincidió con un aumento progresivo pero no explosivo del endeudamiento hipotecario, el promedio nacional de aumento relativo de ese stock en propiedad parcial (en amortización de la hipoteca) fue de 92\%, lo que implicó prácticamente su duplicación. Por ejemplo, en el AMs, con un aumento de 102\% promedio, se dio una correspondencia entre la variación relativa de las viviendas en condición de hipoteca y las que fueron más dinámicas en términos de producción inmobiliaria de nuevas unidades. Por su parte, las periferias metropolitanas alcanzaron niveles de más de 100\%, con las variaciones más importantes en Quilicura, Isla de Maipo, Peñaflor, Puente Alto, Colina, Talagante, Lo Barnechea y Huechuraba (figura 5). El boom continuado desde los ańos ochenta en la construcción de parcelas de agrado, sumado a la construcción de ciudades valladas y precariópolis estatales (Hidalgo et al., 2008), estaría asociado a este aumento del stock en periodo de amortización. El aumento del endeudamiento hipotecario parece haber sido transversal a todos los grupos que componen la geografía social metropolitana: de comunas exclusivas como Lo Barnechea y Las Condes, de clase media emergente como Providencia y más populares como Puente Alto, Maipú o Quilicura. Este patrón puede ser asociado directamente con el despliegue del proceso de metropolización en el AMs y su entorno regional.

En el Área Metropolitana de Valparaíso se dio una mayor disociación entre el aumento relativo del stock habitacional en amortización que deriva de los frentes de expansión metropolitana en comunas como Quilpué y Villa Alemana, y el que proviene del acceso a segundas residencias que pueden o incorporarse a ellos o mantenerse como activo financiero, según ocurrió en Concón, Casablanca, El Tabo, y con menor intensidad en Puchuncaví (figura 5). Aunque la variación relativa fue mucho mayor en estas últimas, siendo de 578\%, 885\% y 236\%, respectivamente, en comunas populares el acceso a la vivienda -primordialmente social y subsidiada por el Estado- se logró gracias a aumentos de 114\% en Villa Alemana o 104\% en Quilpué y 106\% en Limache.

En el Área Metropolitana de Concepción, los niveles de variación relativa fueron menores que en las anteriores. No obstante, se aprecia de nuevo un patrón de aumento del stock en amortización en las periferias metropolitanas, lo que indica que esta variable sigue a la de la producción habitacional destinada al uso directo. En comunas como Chiguayante y Penco la variación absoluta coincidió con un alto cambio relativo de $267 \%$ y $122 \%$, respectivamente, mientras que comunas con una menor variación absoluta, como Florida y Hualqui, presentaron niveles muy altos, con $305 \%$ y $261 \%$, respectivamente.

A pesar de que las incidencias de la expansión del endeudamiento hipotecario detectada a escala nacional y regional entre 2004 y 2015 en esos tres ámbitos metropolitanos no se conocen en detalle, se podría sugerir que, al igual que ocurrió entre 1992 y 2002, las geografías de la deuda hipotecaria siguen respondiendo al desarrollo del mercado habitacional en segmentos relacionados tanto con el valor de uso, como con los que privilegian el valor de cambio; esto es, viviendas para inversión sea en entornos urbanos o en enclaves con amenidades ambientales. La financiarización del consumo de la vivienda, aunque ha permeado transversalmente distintas clases 
y grupos sociales, actúa espacialmente de manera segmentada, acumulándose en las áreas de desarrollo inmobiliario metropolitano más intensivas y dinámicas, sea que correspondan a viviendas de mercado o a viviendas sociales.

Los mapas de la figura 6 sintetizan las geografías regionales de la deuda. Incluyen no solo los montos totales promedio por periodo (el stock), sino la participación porcentual de cada región en el total de las colocaciones hipotecarias nacionales y un índice de intensidad, que es un puntaje estandarizado derivado de la deuda hipotecaria per cápita en cada una. Reflejan además, en conjunto, los distintos niveles de exposición a crisis en el ámbito de la financiación habitacional, puesto que combinan la proporción de colocaciones de este tipo respecto a créditos de corto plazo (consumo) y productivos (inmovilización de capitales ficticios por largos periodos de tiempo), así como la intensidad per cápita del endeudamiento hipotecario que da cuenta de esa 'dispersión social' de la deuda. Así, las regiones de Antofagasta, Metropolitana y la de Coquimbo serían las más expuestas social y espacialmente desde el punto de vista de las geografías sociales de la deuda hipotecaria a los embates que se puedan generar en la acumulación de capital. Desde luego no serían las únicas, ya que -como evidencia el análisis- las geografías sociales de la deuda hipotecaria se han dispersado a lo largo y ancho del país. 

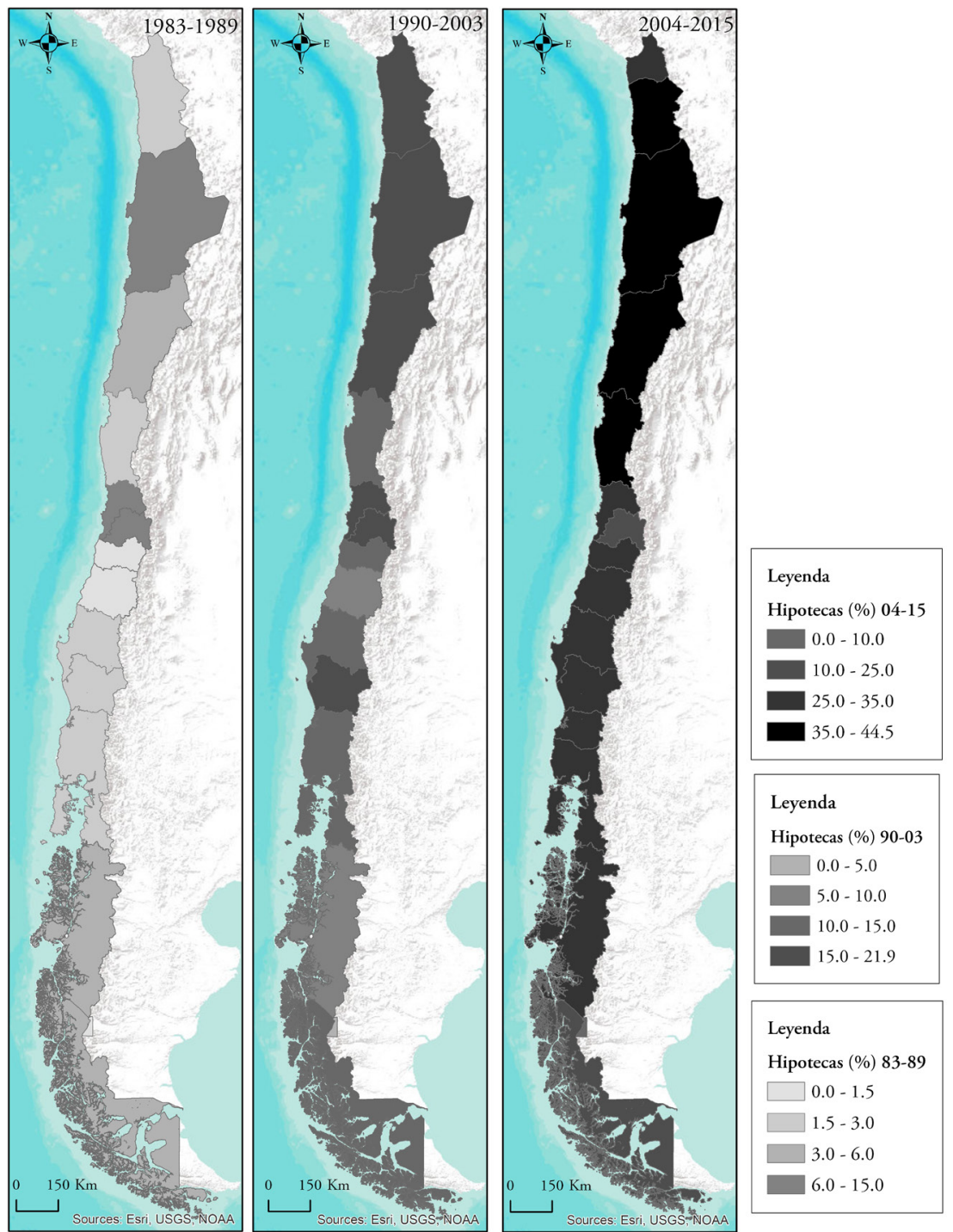

Leyenda

Hipotecas (\%) 90-03

$0.0-5.0$

$5.0-10.0$

$10.0-15.0$

$15.0-21.9$

Leyenda

Hipotecas (\%) 83-89

$\square 0.0-1.5$

$\square 1.5-3.0$

$\square 3.0-6.0$

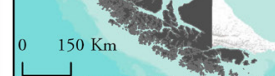

$6.0-15.0$

FIGURA 3 | Peso en porcentaje de las colocaciones hipotecarias respecto a los demás créditos (productivos y de consumo)

FUENTE: ELABORACIÓN PROPIA A PARTIR DE DATOS SBIF (I983 A 20I5) 

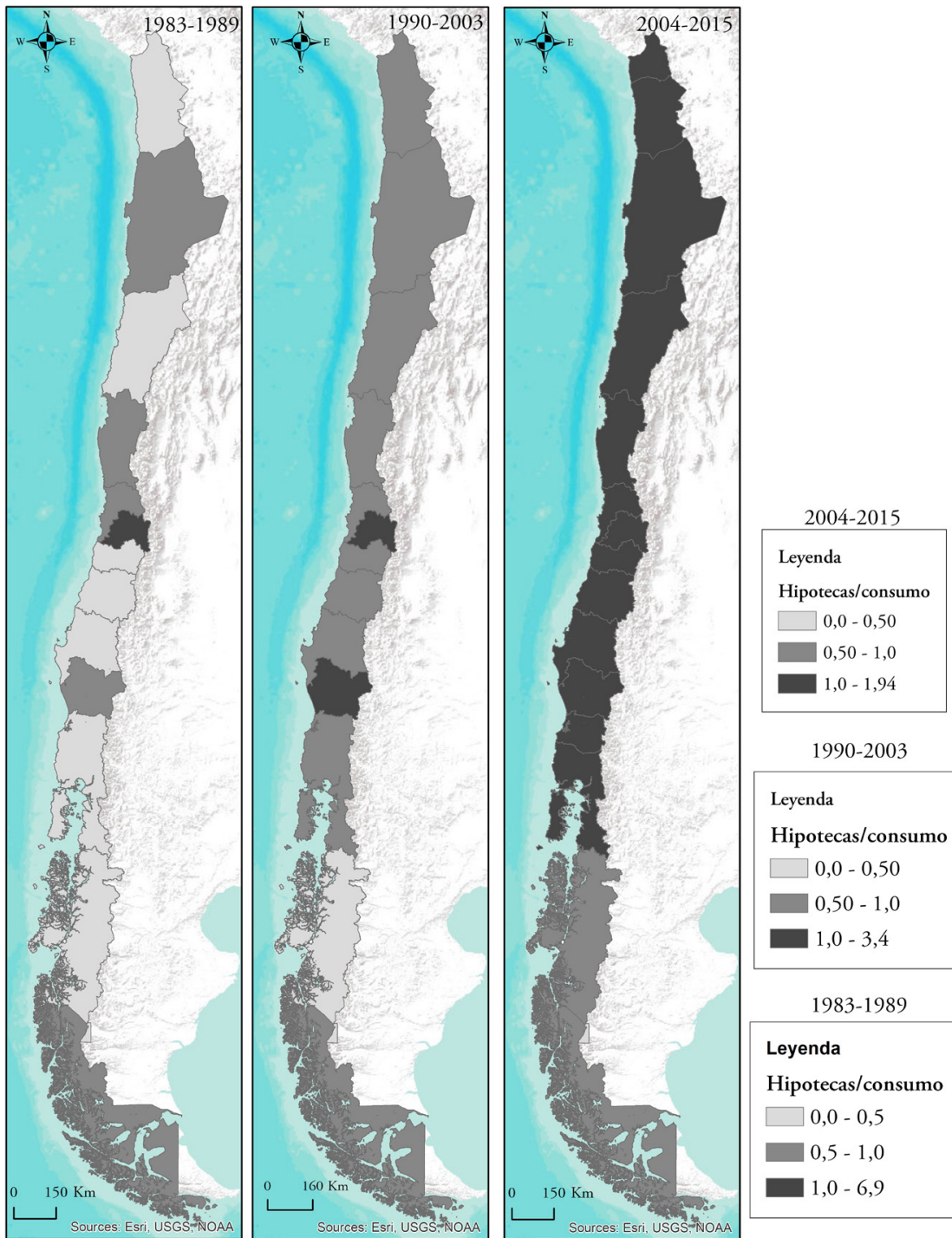

1990-2003

Leyenda

Hipotecas/consumo

$\square 0,0-0,50$

$0,50-1,0$

$1,0-3,4$

1983-1989

Leyenda

Hipotecas/consumo

$\square 0,0-0,5$

$0,5-1,0$

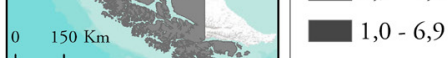

FIGURA 4 | Razón entre créditos hipotecarios y créditos de consumo, promedios por periodo

FUENTE: ELABORACIÓN PROPIA A PARTIR DE DATOS SBIF (I983 A 2OI 5 ) 

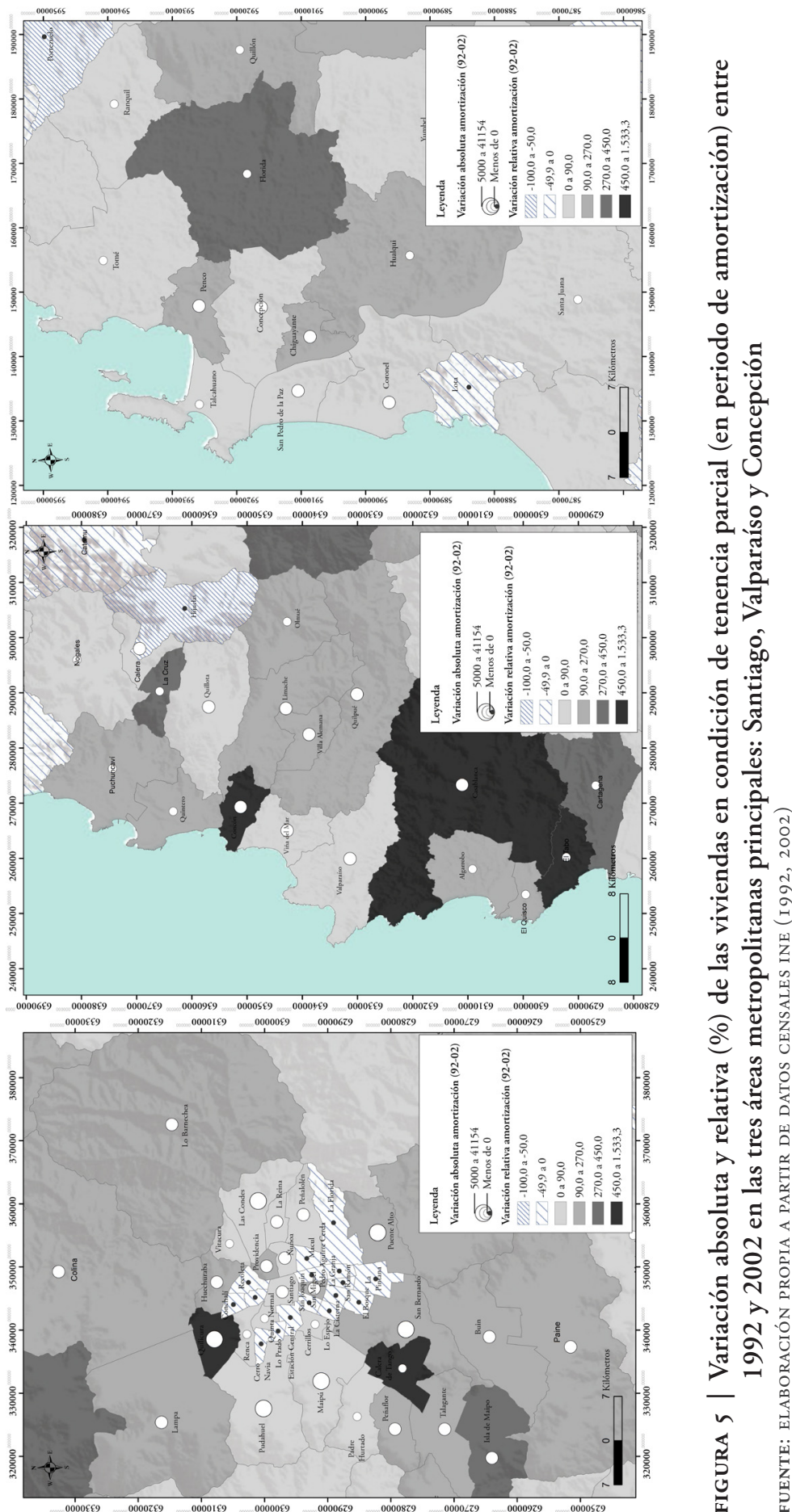

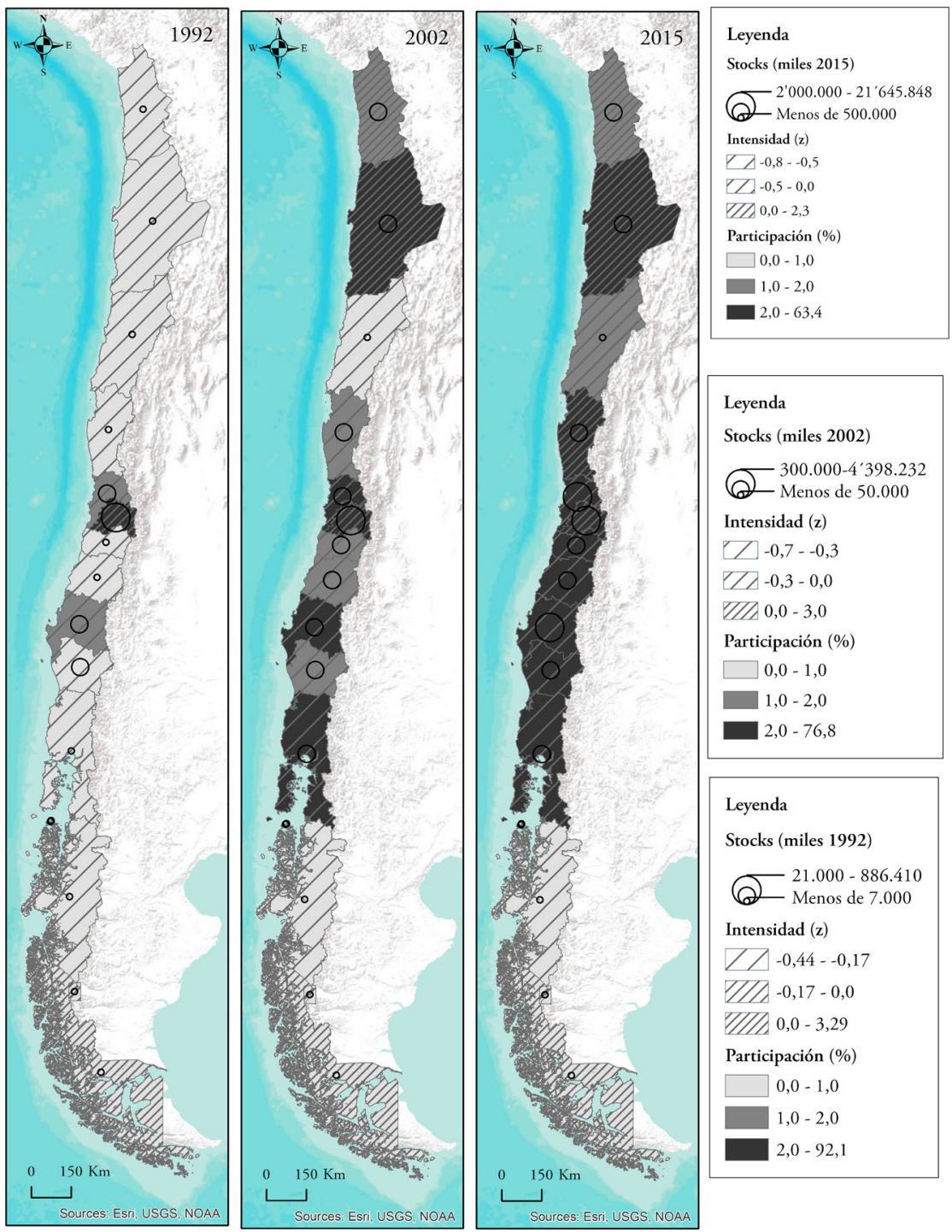

FIGURA 6 | Stocks de deuda hipotecaria, participación regional e intensidad per cápita del crédito habitacional

FUENTE: ELABORACión PROPIA A PARTiR DE DATOS SBIF (I983 A 20I5) 


\section{Conclusiones}

La introducción hecha al proceso contemporáneo de producción de las geografías de la deuda habitacional en Chile confirma que la construcción de más de 3 millones de nuevas unidades residenciales entre 1970 y 2015 en un país que recientemente pasa de los 17 millones de habitantes (Santana, 2018a), ha dejado como resultado un creciente endeudamiento de los hogares. Se trata de una situación que tiende a dispersarse espacialmente, conforme avanzan la urbanización y las condiciones regulatorias favorables a la especulación inmobiliaria en ciertos enclaves atractivos. Tal proceso se debió en parte importante a la financiarización de la producción inmobiliaria que ha promovido la centralización de capitales, con la consecuente transformación de las prácticas de inversión del sector de edificación y la sujeción de las empresas del sector a las lógicas de las finanzas y del mercado de capitales (Santana, 2018a). En este contexto, es claro que la financiarización del consumo inmobiliario se ha constituido en el proceso socioespacial de mayor alcance y relevancia asociado a la utopía neoliberal de la vivienda (Hidalgo et al., 2016).

Se comprobó que la financiarización del consumo habitacional iniciada de manera temprana a fines de los setenta -promovida por el gobierno dictatorial y el gremio más importante de la construcción- ha extendido social y espacialmente el endeudamiento hipotecario en el país, en un proceso homólogo al que han estudiado en otros casos autores como Méndez (2018) y Aalbers (2017). No obstante tal semejanza, su ritmo apunta a una intensificación mucho mayor desde comienzos del siglo xxi. Esto último obedece en cierta medida a las reformas financieras del mercado de capitales promovidas por los gobiernos de la Concertación entre 1994 (con el marco para la securitización de deudas) y 2002 (la vinculación de los mutuos endosables como mecanismo de financiamiento de vivienda social). Pero de mucho mayor peso en ello fue la introducción por parte de la banca privada (en especial, la española) de créditos no endosables en mercados secundarios, instrumentos cuyo precio es menor a mecanismos de financiarización de la producción del espacio, como las letras y los mutuos endosables.

En conjunto con esa circunstancia y un proceso de medianización social que se manifiesta fundamentalmente en los espacios urbanos (Link, Valencia, \& Fuentes, 2015), la geografía de la deuda se ha dispersado desigualmente por el territorio chileno. Tanto su dispersión como su hiperconcentración en ciertas regiones y enclaves metropolitanos sugieren, dado el tipo de mercado habitacional con el cual se yuxtaponen, que hay distintos 'sujetos endeudados': un primer tipo incluye sujetos endeudados subsidiados, que aspiran a alcanzar la propiedad de sus viviendas dándoles exclusivamente un valor de uso (los frentes de expansión de la vivienda social registran alto endeudamiento); un segundo tipo corresponde a sujetos endeudados que acceden a viviendas de mercado también con el interés del valor de uso (en frentes de urbanización de clases medias y altas); y finalmente, sujetos endeudados que acceden a una o más viviendas adicionales con el objetivo de invertir (sea para acrecentar su patrimonio o para mejorar su ingreso familiar), lo que implica la presencia de geografías de la deuda en entornos con amenidades ambientales (segundas residencias en bordes costeros, en enclaves montañosos, 
lacustres, etcétera) o con una accesibilidad urbana importante que facilite su alquiler (departamentos, por ejemplo).

Desde luego, los complejos procesos de subjetivación neoliberal y financiarizada que se asocian a esos tipos, con los encadenamientos de subsidio, deuda y propiedad y sus geografías, son una línea de investigación que está por desarrollarse, quizá en escalas más detalladas y con técnicas de investigación cualitativas. Sin embargo, no es la única que debe abordarse con urgencia. Si bien el sueño de la propiedad de la vivienda es una de las utopías neoliberales que han movilizado políticamente a distintos gobiernos chilenos desde los ańos setenta (Alvarado, 2019; Hidalgo et al., 2016; Santana, 2018a), la cada vez más estrecha articulación entre las hipotecas, los mercados de capitales y la expansión acelerada de la deuda habitacional, identificada en el presente análisis, plantea serias contradicciones que podrían desembocar en una pesadilla de la deuda. La secuencia planteada por Harvey (1990) de sobreinversión en ambiente en el circuito secundario, que desemboca en una sobreproducción evidenciada en distintos segmentos del sector de la construcción, en este caso de vivienda, facilita procesos de hinchamiento de burbujas especulativas, instigados por créditos baratos y expectativas ideológicamente infundidas de que el proceso puede seguir reproduciéndose a perpetuidad en el tiempo. Cualquier crisis, local, nacional o sistémica puede hacer estallar los precios y las hipotecas, con lo cual se dan sendas dinámicas de desposesión de los insolventes (Méndez, 2018) y fenómenos de alienación socioespacial vinculados con la pérdida del patrimonio, del ingreso, de las redes de apoyo cercanas y demás asociadas con el valor de uso de las viviendas. El caso de Chile, con sus intensificadas geografías de la deuda alentadas por créditos relativamente baratos y por rápidos aumentos del precio de la vivienda, ${ }^{8}$ y a pesar de su temprana financiarización, demuestra que, finalmente, ese proceso se encuentra atravesado por contradicciones generales y latentes propias de la acumulación de capital.

\section{Agradecimientos}

Este artículo deriva en parte de la tesis doctoral "Geografías de la acumulación por urbanización en Chile (1975-2015): ¿utopías de la vivienda, distopías urbanas?” financiada por Conicyt (Conicyt-PCHA/Doctorado nacional 3318/2016) y se terminó en el curso del proyecto de investigación Desarrollo urbano, vivienda y familia. Casos de estudio: Madrid y Medellín, y sus áreas metropolitanas adscrito al ciDi y al grupo de investigación en Arquitectura, Urbanismo y Paisaje de la Universidad Pontificia Bolivariana.

Según datos de la Cámara Chilena de la Construcción, los precios se han incrementado 1,8 veces en la última década, y ello según estimaciones muy conservadoras (Banco Central de Chile, 2016). Por otra parte, los precios de la vivienda son una variable política de difícil manejo. 


\section{Referencias bibliográficas}

Aalbers, M. (2011). Place, exclusion, and mortgage markets. Oxford: Wiley-Blackwell.

Aalbers, M. (2017). The financialization of housing. A political Economy approach. Londres: Routledge.

Arrighi, G. (1994). El largo siglo XX. Madrid: Akal.

Alvarado, V. (2019). La faceta espacial del Estado neoliberal chileno: estructura subsidiaria residencial y propiedad en la región urbana central (1990-2016). Tesis de doctorado. Instituto de Geografía, Pontificia Universidad Católica de Chile, Santiago de Chile.

Banco Central de Chile. (2016). Base de Datos Estadísticos. Índice de Valor Promedio (IVP), 2016. https://si3.bcentral.cl/siete/secure/cuadros/arboles.aspx

Brenner, R. (1999). Turbulencias en la economia mundial. Santiago, Chile: LOM-CendaEncuentro XxI.

Cámara Chilena de la Construcción (cCHC). (1973). Plan Habitacionaly de Desarrollo Urbano, 1974-1979. Santiago de Chile: Cámara Chilena de la Construcción.

Capel, H. (2013). La morfología de las ciudades. Tomo III: Agentes urbanos y mercado inmobiliario. Barcelona: Ediciones del Serbal.

Castells, M. (1978). La cuestión urbana (6a ed.). México: Siglo Veintiuno Editores.

Cattaneo, R. (2011). Los fondos de inversión inmobiliaria y la producción privada de vivienda en Santiago de Chile: ¿Un nuevo paso hacia la financiarización de la ciudad? EURE, 37(112), 5-22. http://dx.doi.org/10.4067/S0250-71612011000300001.

CEsifo DICE. (2015). Report: Mortgages in Europe. https://www.cesifo.org/en

Centro de Estudios Públicos (CEP). (1992 [1973]). El Ladrillo. Bases de la politica económica del gobierno militar chileno. https://www.cepchile.cl/cep/site/docs/20160812/20160 812124819/libro_elladrillo_cep.pdf

Corporación de Investigación, Estudio y Desarrollo de la Seguridad Social (Ciedess). (1995). Políticas de financiamiento habitacional en Chile. Primer seminario internacional sobre la experiencia chilena en financiamiento habitacional. Octubre '93. Santiago de Chile: Ciedess / Cámara Chilena de la Construcción (CCHC).

Daher, A. (2013). Territorios de la financiarización y de las crisis inmobiliarias. Revista de Geografía Norte Grande, 56, 7-30. http://dx.doi.org/10.4067/S0718-34022013000300002

Daher, A. (2016). De cómo Chicago transformó a Santiago: 40 años de gobernanza de mercado. En A. Orellana, F. Link, \& J. Noyola (eds.), Urbanización planetaria y la reconstrucción de la ciudad (pp. 141-168). Santiago de Chile: Colección Estudios Urbanos / RIL Editores.

Daher, A \& Moreno, C. (2016). Crisis financiera y sustentabilidad socioeconómica subnacional. Lecturas de Economía, 85, 211-242. http://dx.doi.org/10.17533/udea.le.n85a07

De Mattos, C. (2015). Revolución Urbana. Estado, mercado y capital en América Latina. Santiago: Colección Estudios Urbanos uc / RIL Editores.

Díaz, J., Lüders, R., \& Wagner, G. (2016). Chile 1810-2010. La República en cifras. Santiago: Ediciones UC.

Fox-Gotham, K. (2012). Creating liquidity out of spatial fixity: the secondary circuit of capital and the restructuring of the us Housing Finance System. En M. Aalbers (ed.), Subprime cities. The political economy of mortgage markets (pp. 25-52). Oxford: Blackwell. 
Gárate, M. (2012). La revolución capitalista de Chile (1973-2003). Santiago de Chile: Ediciones Universidad Alberto Hurtado.

Harvey, D. (1985). The urbanization of capital. Studies on history and theory of capitalist urbanization. Oxford: Basil Blackwell.

Harvey, D. (1990). Los límites del capitalismo y la teoría marxista. México, DF: Fondo de Cultura Económica.

Harvey, D. (2013). Ciudades rebeldes. Del derecho a la ciudad a la revolución urbana. Madrid: Akal.

Hidalgo, R. (2005). La vivienda social en Chile y la construcción del espacio urbano en el Santiago del siglo XX. Santiago de Chile: Pontificia Universidad Católica de Chile / Centro de Investigaciones Diego Barros Arana.

Hidalgo, R., Borsdorf, A., \& Zunino, H. (2008). Las dos caras de la expansión residencial en la periferia metropolitana de Santiago de Chile: precariópolis estatal y privatópolis inmobiliaria. En P. Pereira \& R. Hidalgo (eds.), Producción inmobiliaria y reestructuración metropolitana en América Latina (pp. 167-195). Santiago, Chile: Facultad de Arquitectura y Urbanismo, Universidad de São Paulo (fausp) / Instituto de Geografía, P. Universidad Católica de Chile (PUC). https://doi.org/10.13140/ rg.2.1.1808.8723

Hidalgo, R., Santana D., \& Alvarado, V. (2016). Mitos, ideologías y utopías neoliberales de la producción del espacio: hacia una agenda de investigación alternativa. En R. Hidalgo, D. Santana, V. Alvarado, F. Arenas, A. Salazar, C. Valdebenito, \& L. Álvarez (eds.), En las costas del neoliberalismo. Naturaleza, urbanización y producción inmobiliaria: experiencias en Chile y Argentina (pp. 24-66). Santiago, Chile: P. Universidad Católica de Chile-Geolibros.

Instituto Nacional de Estadística (INE), Chile. (1992). Censo de Población y Vivienda 1992: archivos magnéticos Redatam. Santiago de Chile: INE.

Instituto Nacional de Estadística (INE), Chile. (2002). Censo de Población y Vivienda 1992: archivos magnéticos Redatam. Santiago de Chile: INE.

Kurz, R. (2016). El colapso de la modernización. Del derrumbe del socialismo de cuartel al derrumbe de la economía mundial. Buenos Aires: Editorial Marat.

Lazzarato, M. (2013). La fábrica del hombre endeudado. Ensayo sobre la condición neoliberal. Buenos Aires: Amorrortu.

Lefebvre, H. (1976 [1973]). Espacio y política. El derecho a la ciudad II. Barcelona: Ediciones Península.

Lefebvre, H. (1980 [1970]). La revolución urbana. Madrid: Alianza Editorial.

Lefebvre, H. (2013 [1974]). La producción del espacio. Madrid: Capitán Swing.

Lencioni, S. (2014). Reestruturação imobiliária: uma análise dos processos de concentração e centralização do capital no setor imobiliário. EURE, 40(120), 29-47. http://dx.doi. org/10.4067/S0250-71612014000200002

Link, F., Valenzuela, F., \& Fuentes, L. (2015). Segregación, estructura y composición social del territorio metropolitano en Santiago de Chile. Complejidades metodológicas en el análisis de la diferenciación social en el espacio. Revista de Geografía Norte Grande, 62, 151-168. http://dx.doi.org/10.4067/S0718-34022015000300009

Méndez, R. (2018). La telaraña financiera. Una geografía de la financiarización y su crisis. Santiago: Colección Estudios Urbanos Uc / RIL Editores. 
Merrifield, A. (2014). The new urban question. Londres: Pluto Press.

Pereira, P. (2008). Produçấo imobiliária e crise da cidade na emergência de uma nova forma de metrópole na América Latina. En P. Pereira \& R. Hidalgo (eds.), Producción inmobiliaria y reestructuración metropolitana en América Latina (pp. 55-65). Santiago de Chile: Facultad de Arquitectura y Urbanismo, Universidad de São Paulo (fausP) / Instituto de Geografía, P. Universidad Católica de Chile (puc). https://doi. org/10.13140/rg.2.1.1808.8723

Rolnik, R. (2017). La guerra de los lugares. La colonización de la tierra y la vivienda en la era de las finanzas. Santiago de Chile: LOM.

Santana, D. (2018a). Geografias de la acumulación por urbanización en Chile (1975-2015): ¿utopias de la vivienda o distopias urbanas? Tesis de doctorado, Instituto de Geografía, Pontificia Universidad Católica de Chile. https://repositorio.uc.cl/handle/11534/22326

Santana, D. (2018b). Aproximaciones a la producción financiera del espacio: de las geografías de las finanzas a las de la financiarización. En J. Montoya (ed.), Temas y problemas en geografía humana (pp. 155-178). Bogotá DC: Universidad Nacional de Colombia.

Santana, D. (2019). La teoría de lo inmobiliario más allá de la 'vieja cuestión urbana'. Bases para una economía política del espacio. En R. Hidalgo, D. Santana, \& Alvarado, V. (eds.), Las geografías del neoliberalismo en América del Sur. Ensayos descriptivos, críticos y necesarios. Serie GEOlibros N. ${ }^{\circ}$ 30. Santiago de Chile: Instituto de Geografía, P. Universidad Católica de Chile.

Santana, D. \& Alzate, A. (2017). Las teorías críticas sobre la producción inmobiliaria: dos perspectivas metromarxistas y una agenda de investigación. En D. Hiernaux \& C. González (eds.), La ciudad latinoamericana a debate: Perspectivas teóricas (pp. 155192). Querétaro: Universidad Autónoma de Querétaro.

Superintendencia de Bancos e Instituciones Financieras de Chile (SBIF). (1982-2016). Información Financiera. Santiago, Chile: SBIF.

Superintendencia de Bancos e Instituciones Financieras de Chile (sBIF). (2017). Financiamiento de vivienda. http://www.sbif.cl/sbifweb/servlet/InfoFinanciera?indice=4.1\&idCategor ia $=564 \&$ tipo

Theurillat, T. (2010). La financiarisation de l'immobilier et la durabilité. Le cas des investissements immobiliers des caisses de pension suisses. Saarbrücken: Éditions Universitaires Européennes (EUE).

Topalov, C. (1979). La urbanización capitalista: algunos elementos para su análisis. México: Edicol.

Wallerstein, I. (2015). La crisis estructural, o por qué los capitalistas no encuentran gratificante al capitalismo. En I. Wallerstein, R. Collins, M. Mann, G. Derluguian, \& C. Calhoun, ¿Tiene futuro el capitalismo? (pp. 15-46). México, DF: Siglo Xxi Editores. 